\title{
Testosterone and estradiol affect adolescent reinforcement learning
}

\author{
Sina Kohne ${ }^{\text {Corresp., } 1}$, Esther K. Diekhof ${ }^{2}$ \\ 1 Faculty of Mathematics, Informatics and Natural Sciences, Department of Biology, Institute of Zoology, Neuroendocrinology and Human Biology Unit, \\ Universität Hamburg, Hamburg, Germany \\ 2 Faculty of Mathematics, Informatics and Natural Sciences, Department of Biology, Institute of Zoology, Neuroendocrinology and Human Biology Unit, \\ Universtität Hamburg, Hamburg, Germany \\ Corresponding Author: Sina Kohne \\ Email address: sina.korf@uni-hamburg.de
}

During adolescence, gonadal hormones influence brain maturation and behavior. The impact of $17 \beta$-estradiol and testosterone on reinforcement learning was previously investigated in adults, but studies with adolescents are rare. We tested 89 German male and female adolescents (mean age $\pm s d=14.7 \pm 1.9$ years) to determine to what extent $17 \beta$-estradiol and testosterone influence reinforcement learning capacity in a response time adjustment task. Our data showed, that $17 \beta$-estradiol correlated with an enhanced ability to speed up responses for reward in both sexes, while the ability to wait for higher reward correlated with testosterone primary in males. This suggests that individual differences in reinforcement learning may be associated with variations in these hormones during adolescence, which may shift the balance between a more reward- and an avoidance-oriented learning style. 


\section{Testosterone and estradiol affect adolescent reinforcement learning}

2

3

4

5

6

7

8

9

10

11

12

13

14

15

16

17

18

19

20

21

22

23

24

25

26

27

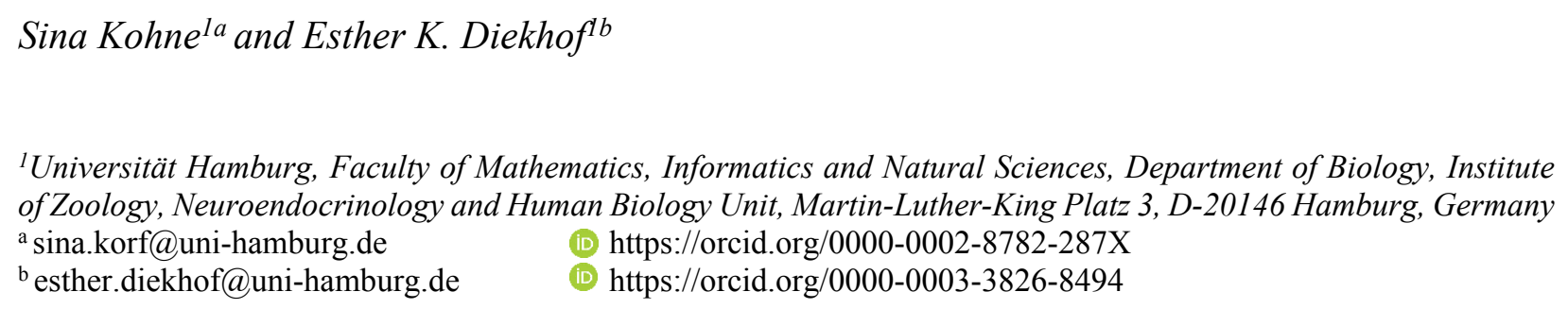




\section{Abstract}

During adolescence, gonadal hormones influence brain maturation and behavior. The impact of $17 \beta$-estradiol and testosterone on reinforcement learning was previously investigated in adults, but studies with adolescents are rare. We tested 89 German male and female adolescents (mean age $\pm \mathrm{sd}=14.7 \pm 1.9$ years) to determine to what extent $17 \beta$-estradiol and testosterone influence reinforcement learning capacity in a response time adjustment task. Our data showed, that 17ßestradiol correlated with an enhanced ability to speed up responses for reward in both sexes, while the ability to wait for higher reward correlated with testosterone primary in males. This suggests that individual differences in reinforcement learning may be associated with variations in these hormones during adolescence, which may shift the balance between a more reward- and an avoidance-oriented learning style.

\section{Introduction}

Sex hormones have a great impact on adolescent (neuro-)physiological maturation. With the onset of puberty at 9 to 10 years in girls and 10 to 12 years in boys, respectively, sex hormone level increases rapidly (Peper \& Dahl, 2013). Sex hormone levels are regulated via the reproductive hypothalamic-pituitary-gonadal axis initiated by the secretion of hypothalamic gonadotropin releasing hormone $(\mathrm{GnRH})$. $\mathrm{GnRH}$ thereby stimulates the synthesis and secretion of luteinizing hormones and follicle stimulating hormones in the pituitary, which in turn contribute to the maturation of the gonads and sex hormone secretion (Sisk \& Foster, 2004).

The rising sex hormone level during adolescence significantly contributes to pubertal development. With attainment of sexual maturity, sex hormones maintain reproductive function (Sisk \& Foster, 2004). Neurophysiological investigations demonstrated a different impact of testosterone and $17 \beta$-estradiol $\left(\mathrm{E}_{2}\right)$ on brain maturation. Testosterone is related to an increase of global white and gray matter volume in male adolescents (Peper et al., 2009, 2011), whereas in female adolescents $E_{2}$ may be negatively associated with gray matter volume (Peper et al., 2009). Further, $\mathrm{E}_{2}$ seems to predict white matter growth across the entire brain in both sexes (Herting et al., 2014). Moreover, neurophysiological developmental changes during adolescence could be better explained by hormonal and pubertal development (measured by the Pubertal Development Scale or Tanner Stages) than by chronological age (Herting et al., 2014; Wierenga et al., 2018).

Sex hormones are very important when it comes to behavior and cognitive function in animals and humans. Besides the impact of $\mathrm{E}_{2}$ and testosterone on adolescent reward-related risk-taking (i.a. Op de Macks et al., 2016), an influence on reward-related learning and cognition has been assumed as well (Diekhof, 2018; Hamson et al., 2016). In adult women, $\mathrm{E}_{2}$ may promote verbal memory and fluency (Hamson et al., 2016). In gonadectomized male and female rats, $E_{2}$ was found to improve learning and memory even after physiological or psychological stressors (Hamson et al., 2016; Khaleghi et al., 2021). Moreover, studies with castrated male rats suggested that learning may be improved by testosterone treatment (Spritzer et al., 2011). In healthy older men, a short-term testosterone administration improved cognitive performance significantly (Cherrier et al., 2001). Findings from children (6 to 9 years) further showed a relation between moderate testosterone levels and an average intelligence (IQ between 70 and 130), whereas enhanced testosterone concentrations were related to high (IQ > 130), but also low intelligence (IQ < 70) (Ostatníková et al., 2007). Other studies also reported enhanced testosterone concentrations in children and young adolescents (6 to 13 years) with learning 
71 disabilities compared to peers without impairments (Kirkpatrick et al., 1993). Given this evidence, one may assume that during early adolescence balanced testosterone concentrations may be important for efficient cognitive processing.

One way for sex hormones to modulate aspects of reward processing and reinforcement learning is through the neurotransmitter dopamine. Both estradiol and testosterone can act as natural dopamine-agonists, which promote dopamine release and dopaminergic transmission through various physiological mechanisms (Becker, 1990; Castner et al., 1993; Pasqualini et al., 1995; Sinclair et al., 2014). This is in so far important, since dopamine plays a crucial role in reinforcement learning and determines how proficient individuals learn from positive or negative action outcomes. It has been assumed that changes in dopamine following so called reward prediction errors possibly act via two anatomically distinct pathways in the mesocorticolimbic dopamine system (Maia \& Frank, 2011). The activation of the Go pathway after the dopamine burst that follows unexpected reward entails in a repetition of the same action. In turn, activation of the NoGo pathway results from a dip in the tonic dopamine level, which facilitates learning from unexpected reward reduction, omission, or even punishment. This optimally promotes an adaption of action choice to maximize overall reward (Frank et al., 2004)

A study using a response time (RT) adaption task, the so-called "clock task", demonstrated this relation between dopamine and reinforcement learning by showing that patients with Parkinson's disease, but pharmacologically normalized dopamine concentration, were better in the Go learning aspect of the task. These medicated patients thereby showed an enhanced ability to speed up for a reward (i.e., better ability to acquire a higher reward through quickly responding after trial onset). In comparison, in an unmedicated state and thus with pathologically lowered dopamine, the same patients, demonstrated a better NoGo learning ability. This was indicated by an increased capacity to slow down responding for reward maximization (i.e., enhanced capacity to wait for higher reward) (Moustafa et al., 2008).

With the same task, Diekhof and colleagues characterized the impact of periodically fluctuating sex hormones in women on Go as opposed to NoGo learning ability. They compared the RT adaption during three different menstrual cycle phases of late luteal phase, luteal phase and early follicular phase. During the late follicular phase $\mathrm{E}_{2}$ is high and progesterone still remains low. In the luteal phase progesterone nears its maximum (Reimers et al., 2014), whereas in the early follicular phase $\mathrm{E}_{2}$ and progesterone are at their nadir (Diekhof, 2015). Reimers and colleagues (2014) concluded that heightened $\mathrm{E}_{2}$ during the late follicular phase impaired the ability to slow down for reward maximization (NoGo learning ability), as opposed to the ability to speed up for higher reward (Go learning capacity). Diekhof (2015) extended these findings by showing a positive correlation between $\mathrm{E}_{2}$ and the ability to speed up for reward during the early follicular phase. This latter study indicated a better Go vs. NoGo learning ability during the early follicular phase and assumed that the boosting influence of the still increasing, yet intermediate $\mathrm{E}_{2}$ on dopamine probably optimally promotes Go learning ability.

Regarding the impact of testosterone on reward processing and reinforcement learning, data from humans are currently sparse. Also, rodent studies provide inconsistent findings about the influence of testosterone on reward processing. It has been observed that testosterone administration enhanced tyrosine hydroxylase (the rate-limiting enzymes catalyzing dopamine synthesis) in the substantia nigra of gonadectomized adolescent male rats (Purves-Tyson et al., 2012). Yet, testosterone may reduce tyrosine hydroxylase in gonadally intact adolescent male rats in the caudate putamen (Wood et al., 2013). Further, testosterone administration in gonadectomized adolescent male rats enhances mRNA of the dopamine degrading enzymes 
117 catechol-O-methyltransferase and monoamine oxidase in the substantia nigra (Purves-Tyson et

118 al., 2012). In contrast, testosterone led to a significant increase of dopamine in the nucleus

119 accumbens and dorsal striatum of gonadally intact male rats. Finally, in humans testosterone has

120 been found to enhance striatal activity in the context of reward processing, while it decreased

121 activation of the striatum during punishment processing (Morris et al., 2015).

122

123

Previous studies with early adolescents and young adults could not find a relation between testosterone and performance in cognitive or reward-related tasks (Halari et al., 2005;

124

125

126

127 Ladouceur et al., 2019; White et al., 2020). Therefore, no clear assumptions can be made regarding the influence of testosterone on Go and NoGo learning. However, in light of its physiological significance for dopaminergic processing, a positive influence on reward processing and the Go learning may be assumed.

128

129

130

131

132

133

134

135

136

137

138

139

140

141

142

143

144

\section{5}

146

147

148

149

150

151

152

153

154

155

156

\section{Current study}

In the present study, we assessed response time adjustments and learning behavior in the context of reward maximization in an adolescent sample. The salivary $\mathrm{E}_{2}$ and testosterone concentration was measured on the test day, which enabled us to examine the effect of the two sex hormones on Go and NoGo learning capacity. The adolescents performed an RT adjustment task, the socalled clock task (modified by Diekhof, 2015; created by Moustafa et al., 2008). In line with findings from adult research, we predicted that Go learning, associated with a better capability to speed up responding to maximize reward, would be related to higher $\mathrm{E}_{2}$ concentrations (e.g. Diekhof, 2015; Reimers et al., 2014). Studies reporting behavioral influences of testosterone on reward-related processing and especially reward learning are scarce. Whether higher testosterone levels would positively influence Go learning as well, could not be unconditionally hypothesized. Therefore, we examined the relation of testosterone and reinforcement learning capacity with the same analysis that was used to consider impact of $\mathrm{E}_{2}$. Finally, we hypothesized that the effects of sex hormones on reinforcement learning would be different in female and male adolescents, mostly due to higher $\mathrm{E}_{2}$ concentrations in females and enhanced testosterone in males.

\section{Materials \& Methods}

\section{Participants}

In total, 106 healthy German adolescents, between 11 and 18 years old, participated in this study. All participants had no history of psychiatric or neurological disorders and assured no regular medication intake. Fifteen adolescents were excluded from the analysis, because they showed a random response pattern throughout the task, which suggested that the task instructions had not been properly understood or that the respective participant lacked the motivation to perform the task properly. Another two participants were excluded because of technical problems that left the task unfinished. In sum, the data of 89 adolescents (mean age $\pm \mathrm{SD}=14.74 \pm 1.9$ years; 52 females) were analyzed.

Every participant had to sign a written declaration of informed consent before participation. In the case of minority, a legal guardian (parent) also had to sign a written declaration of informed consent before the testing. The adolescents were recruited in sports and other leisure clubs. The

Peer] reviewing PDF | (2021:04:60632:2:0:NEW 19 Nov 2021) 
157 study protocol was approved by the local ethics committee of the Ärztekammer Hamburg (Ref:

158 PV3948) and the study was conducted in accordance with "The Code of Ethics of the World

159 Medical Association" (Declaration of Helsinki).

160 On the test day, participants were screened for depressive symptoms with the validated

161 German Depression Inventory for Children and Adolescents (Stiensmeier-Pelster et al., 2014).

162 Individual cognitive capacity was tested via the Digit-Span Test by measuring both forward and

163 backward span from the German version of the Wechsler inteligence scale for childen (Wechsler,

164 2014) by counting the numbers that were correctly recalled. Self-reported trait impulsivity was

165 examined with a German Version of the Barratt Impulsiveness Scale (BIS-11) for adolescents

166 (Hartmann et al., 2011). Finally, every participant and the corresponding legal guardian filled out

167 a translated version of the Pubertal Development Scale (PDS) (Petersen et al., 1988). We then

168 calculated a mean of both scores and used it as an indicator of the degree of physical pubertal

169 development of the given participant.

\section{Experimental task}

171 A modified version of the clock task (see Diekhof, 2015), that had been introduced by Moustafa

172

173 et al. (2008) was used. In the task, three differently colored clock faces were presented. A full rotation of the clock arm lasted 5 seconds. Each clock face was assigned to one of three conditions, namely the fast, the random, and the slow condition. Each of the three clock conditions was shown 50 times in three sessions of 50 trials each, resulting in a total of 150 trials. The sequence of clock faces was pseudo-randomized and balanced for trial-type transitions (see also Diekhof, 2015 for further details on the clock task). The fast clock condition required a fast reaction once the clock arm started to move, in order to maximize reward outcome. The slow clock condition, in contrast, required the participant to postpone responding and slower RTs yielded higher reward. The random condition served as a control variant with no contingency between RT and reward outcome. It was used as an indicator of baseline response preference (see Figure 1).

The participants had to adapt to the optimal response speed in each condition to maximize their overall reward. The exact reward value of each trial in the fast and slow condition was calculated with a cosine function, ranging between a minimum of 15 and a maximum of 60 points. The random reward value was calculated with the difference between minimum and maximum points of reward multiplied by a random number and added with the minimum reward value (see Figure 1). In every condition, a random noise parameter (range between -5 to +4 points) was applied to the reward. This was done to disguise the relation of a specific reward outcome with a specific RT. Immediately after the response, the reward outcome was shown to the participant. For the remaining time of a full clock arm turn, a blank screen was shown. Thus, each trial had the same length. If the participant did not respond within 5 seconds, no reward was presented, and the participant had to wait another 5 seconds before the next trial started.

\section{Saliva collection and analyses}

196 In the morning, three saliva samples were collected by the participant in $2 \mathrm{~mL}$ microcentrifuge tubes at home. Sample collection took place over the course of one hour (half-hourly samples)

198 and started directly after awakening. The participants were allowed to drink water after the first 
199 sample up until 5 minutes before the second and third sample. They had to refrain from intake of 200 food and beverages other than water during the sampling hour. Saliva samples were stored at -

$20120^{\circ} \mathrm{C}$ until further use. Before analysis, samples were thawed and centrifuged at room

202 temperature at RCF $604 \times$ g (i.e., $3000 \mathrm{rpm}$ in a common Eppendorf MiniSpin centrifuge) for 5

203

204

205

206

207

208

209

210

211

212

213 minutes to separate the saliva from mucins. For the $\mathrm{E}_{2}$ analysis, a 17- $\beta$-Estradiol Saliva ELISA was used (Limit of Detection: $2.1 \mathrm{pg} / \mathrm{mL}$ ), coated with anti-17- $\beta$-Estradiol antibody (monoclonal) with antibodies derived from donkey and sheep. For the testosterone analysis, a Testosterone Luminescence Immunoassay (both assays from Tecan/IBL International) was utilized (Limit of Detection: $1.8 \mathrm{pg} / \mathrm{mL}$ ), coated with anti-mouse antibody. Intra-assay precision showed a mean CV of $8.8 \%$ (17- $\beta$-Estradiol Saliva ELISA) and 7.3\% (Testosterone Luminescence Immunoassay). Inter-assay precision showed a mean CV of 11.8 (17- $\beta$-Estradiol Saliva ELISA) and $7.3 \%$ (Testosterone Luminescence Immunoassay).

The three morning samples were combined in an aliquot sample that consisted of an equal amount of saliva from every tube $(100 \mu \mathrm{L})$. The analysis was done as described in the respective manual in our in-house laboratory. From the aliquot two samples were assayed $(n=2)$.

214 In addition, a high and a low control were analyzed. Subsequent behavioral analyses were done

215

216 with standardized z-transformed values $\left(z_{i}=\frac{X_{i}-\bar{x}}{S_{x}}\right)$ for each ELISA plate to standardize measurement inaccuracy of the plates.

\section{Data preprocessing}

218 For each subject, we calculated the mean RTs of each clock type. RTs under 200 ms were

219 discarded, since they were very unlikely to reflect voluntary movements. In all, 125 trials (mean

$220 \pm s d: 70 \pm 72 \mathrm{~ms}$ ) under $200 \mathrm{~ms}$ were excluded. We also calculated the mean RT of the initial 12

221

222

223

224

225

226

227

228

229

230

231

232

233

234

235

236

237

238

239

240

241

242 trials (called first block) and of the optimized last 12 trials (called last block) for each condition and participant (see Diekhof, 2015; Kohne et al., 2021; Moustafa et al., 2008; Reimers et al., 2014 for a similar procedure). At the beginning of the experiment (in the first block), the participant did not know which clock face was associated with faster or slower responses for higher reward. Hence, the participant had to try to achieve the optimal outcome via various reactions exploring the task structure. Conversely, at the end of the clock task (in the last block), the participant should have been well adapted and was expected to show optimal RTs that led to the highest reward outcome in relation to individual clock faces.

Apart from the mean RT for the three clock types, the actual learning preferences that reflected individual Go and NoGo learning ability, respectively, were calculated from the last block. They reflected the adaption to the optimal response speed to the slow and fast clock, respectively, and allowed us to test the functional opponency of Go versus NoGo learning. For this, the RT of the slow and the fast clock were calculated in relation to the random clock, which provided information on the individual baseline response speed of a given participant. In order to calculate the optimized responses to the slow clock condition, we first subtracted the mean RT of the last 12 trials of the random clock condition from the mean slow clock RT of the last block. For standardization, this difference was then divided by the mean RT of the last 12 trials from the random clock. The resulting standardized relative RT reflects "optimized relative slowing". Correspondingly, the subtraction of the mean fast clock RT from the mean random RT and its division by the mean random RT was used as the "optimized relative speeding" value.

The individual learning-related change in RT for each clock condition was calculated by subtracting the RT of the first block from the RT of the last block. 


\section{Data analyses}

244 The behavioral data were analyzed with IBM SPSS Statistics 25. First, we performed a repeated measures General Linear Model (GLM) with the factors "clock condition" (fast, random, slow), "block" (first, last), "sex" (female, male) and "age" to test for possible effects of these factors on the RT. In another two GLMs the factor "age" was replaced by either the covariate "pubertal development" (PDS-score) or the z-standardized sex hormone concentration of $\mathrm{E}_{2}\left(\mathrm{zE}_{2}\right)$ and testosterone (zT) (see Results section below). This was done to assess the impact of pubertal maturation and sex hormones level on reinforcement learning. Post hoc tests used paired and independent t-tests, which were Bonferroni-corrected for multiple testing. If Levene's test was

252

253 significant, Welch's t-test instead of Student's t-test was used. The learning preference and effects of covariates were examined with a two-sided Pearson correlation. All effects and differences were considered as significant below a p-value of .05, two-tailed.

\section{Results}

\section{Learning preference}

257

258

259

260

261

262

263

264

Studies with adults revealed a reverse capability for adaptive speeding vs. adaptive slowing of responses in the clock task (Diekhof, 2015; Reimers et al., 2014). Our data demonstrate that this reverse relation in adjustment preferences to either the slow or the fast clock may also exist in adolescents. We found that optimized relative speeding and slowing were negatively correlated in both sexes (females: $r=-.48, p<.001$; males: $r=-.67, p<.001$ ) (see Figure 2). Adolescents who were better adjusted to the last block of the slow clock had difficulties to speed up for reward. In turn, participants who responded faster to the fast clock in the last block were impaired in the ability to slow down for reward.

\section{General group characteristics}

The female and male adolescents did not differ in their age, impulsivity (BIS-11), and $\mathrm{zE}_{2}$ concentration, which was determined by independent t-tests (see Table 1). The only significant differences between the two groups were a significantly higher zT level in males compared to females $\left(t_{43.95}=-6.82, p<.001, d=-1.56\right)$ and a more advanced pubertal development of females compared to males ( mean $_{P D S \text { females }} \pm$ se: $3.03 \pm .07$; mean ${ }_{P D S \text { males }} \pm$ se: $2.72 \pm .09, t_{87}=$ $2.67, p=.009, d=.57)$.

\section{Influence of age and sex on response time adjustments}

In an initial step, we assessed the influence of chronological age and sex of the participant on learning performance. For this, we used a repeated measures GLM including the covariate "age", the between-subjects factor "sex" and the within-subject factors "clock condition" (fast, random, slow) and "block" (first, last). We solely found a significant two-way interaction of clock condition $\mathrm{x}$ block $\left(F_{2,172}=4.41, p=.014, \eta^{2}{ }_{p}=.05\right)$. This was reflected by a change in the RT from the initial to the optimized last block in the fast $\left(t_{88}=11.08, p<.001, d=1.17\right.$, Bonferroni 
279

280

281

282

283

284

285

286

287

288

289

290

291

292

293

294

295

296

297

298

299

300

301

302

303

304

305

306

307

308

309

310

311

312

313

314

315

316

317

318

319

corrected for three comparisons) and in the slow condition $\left(t_{88}=-13.79, p<.001, d=-1.46\right.$, Bonferroni corrected for three comparisons), but not in the random condition $\left(t_{88}=.14, p=1, d\right.$ $=.02$, Bonferroni corrected for three comparisons) (Table 2).

\section{Influence of pubertal development and sex on response time adjustments}

The first GLM was repeated with the factor "pubertal development" (measured with the PDS) replacing the factor "age". A significant main effect of clock condition $\left(F_{2,172}=7.28 p=.001\right.$, $\left.\eta^{2}{ }_{p}=.08\right)$, a significant two-way interactions of clock condition $\mathrm{x}$ pubertal development $\left(F_{2}=\right.$ $\left.3.4, p=.036, \eta^{2}{ }_{p}=.04\right)$ and clock condition $\mathrm{x} \operatorname{sex}\left(F_{2}=3.81, p=.024, \eta^{2}{ }_{p}=.04\right)$ emerged.

Further, the interaction between clock condition and block remained significant $\left(F_{2,172}=8.04, p\right.$ $\left.<.001, \eta_{p}^{2}=.09\right)$.

Post hoc t-tests showed a significant RT distinction between the three clock conditions (fast vs. random: $p<.001, \mathrm{~d}=-1.33$; fast vs. slow: $p<.001, d=-2.75$; slow vs. random: $p<$ $.001, d=1.61$, Bonferroni corrected for two comparisons) (see Table 2). Consequently, an adjustment to the varying clock conditions could be observed. Concerning the interaction between clock condition and sex, a significant difference only arose in the slow clock condition. Males reacted significantly slower and thereby better to the slow clock in general than females $\operatorname{did}(p=.048, d=-.43)$ (see Table 2). The interaction of "pubertal development" and "clock condition" was reflected by a trend-wise positive correlation between the PDS and the RT of the random condition only $(r=.19, p=.068)$ (see Table 2$)$.

\section{Influence of sex hormones and sex on response time adjustments}

In a third GLM we investigated the modulatory influence of $\mathrm{zE}_{2}$ and $\mathrm{zT}$ as a function of the participants' sex on RTs in the three clock conditions (fast, random, slow) and the two blocks (first, last). The main effect of "clock condition" $\left(F_{2}, 160=114.83 p<.001, \eta^{2}{ }_{p}=.81\right)$ and the interaction of "clock condition" and "block" $\left(F_{2}, 160=7.28 p<.001, \eta_{p}^{2}=.59\right)$ remained significant. Furthermore, an interaction of block x clock condition $\mathrm{x} \mathrm{zE_{2 }}$ concentration $\left(F_{2}=4.9\right.$, $\left.p=.009, \eta^{2}{ }_{p}=.06\right)$ and a main effect of block $\left(F_{1,80}=5.29 p=.024, \eta^{2}=.06\right)$ and of $\mathrm{zT}\left(F_{1}=\right.$ $5.28 p=.024, \eta_{p}^{2}=.06$ ) occurred.

The interaction of block $\mathrm{x}$ clock condition $\mathrm{x} \mathrm{zE}_{2}$ was reflected by a negative correlation between $\mathrm{zE}_{2}$ and the initial $\mathrm{RT}$ in the fast clock condition $(r=-.24, p=.03)$ (see Figure 3$)$. In addition, we also examined the individual learning-related change in the RTs between first and last block, which demonstrated the adjustment from the initial to the optimized block (RT last block - RT first block). The learning-related change showed a significant positive correlation with $\mathrm{zE}_{2}$ in the fast clock condition $(r=.28, p=.01)$ (see Figure 4$)$. No correlation emerged with the slow $(r=.08, p=.497)$ or random condition $(r=-.18, p=.096)$.

A post-hoc comparison of the blocks evinced a slower response speed in the initial block compared to the last block $\left(t_{88}=-2.67, p=.009, d=-.28\right)$. Further, zT was positively correlated with a slower RT independent of clock condition or block $(r=.29, p=.007)$ (see Figure 5). Since we found a significant difference in the zT of females and males, with higher concentrations in males (see Table 1), we additionally explored the zT effect separately for both sexes. From this, it became obvious that the correlation probably emerged from the male adolescents. Accordingly, the mean of both blocks across all clocks was positively correlated 
320

321

322

323

324

325

326

327

328

329

330

331

332

333

334

335

336

337

338

339

340

341

342

343

344

345

346

347

348

349

350

351

352

353

354

355

356

357

358

359

360

361

362

363

with zT in males $(r=.48, p=.002)$, but not in females $(r=-.15, p=.298)$. In males, a general slowing could also be observed with increasing zT in both blocks of all conditions (first: $r=.37$, $p=.025$, last: $r=.5, p=.002)$ and especially in the slow $(r=.42, p=.01)$ and the random $(r=$ $.35, p=.032)$, but not in the fast condition $(r=.09, p=.579)$. Additionally, in the initial $(r=$ $.35, p=.036)$ and optimized block $(r=.44, p=.007)$ of the slow clock positive correlations emerged. Again, these correlations could not be found in females.

\section{Discussion}

This study examined the effects of adolescent $\mathrm{E}_{2}$ and testosterone concentrations on RT adjustments in the clock task. Results indicate individual differences in the preference for either Go or NoGo learning (see Figure 2) and an adaption to the different clock conditions from the initial to the optimized block. Both findings have already been demonstrated previously in studies with adults (Kohne et al., 2021; Moustafa et al., 2008; Reimers et al., 2014). In addition, we also found that testosterone levels were significantly higher in males then females, while age, impulsivity and $\mathrm{E}_{2}$ concentrations did not differ between the sexes. We also did not observe an age-dependent influence on the RT, and there was no association between individual pubertal development and Go or NoGo learning. Solely, a tendency towards a slower baseline response speed with increasing pubertal development emerged. Apart from that, we found a sex difference in the slow clock condition. Male adolescents responded significantly slower (better adapted) to the slow clock condition compared to females. $\mathrm{E}_{2}$ and testosterone further appeared to modulate learning ability in different ways. Whereas $\mathrm{E}_{2}$ apparently enhanced initial Go learning (see Figure 3 and 4), testosterone presumably promoted NoGo learning ability (see Figure 5), yet primarily in males.

Similar to studies with adults, our data confirmed the detection of a preference for Go or NoGo learning ability with a presumable supporting effect of $\mathrm{E}_{2}$ on Go learning (Diekhof, 2018; Moustafa et al., 2008; Reimers et al., 2014). Furthermore, we observed a relation between habitual testosterone and the ability to slow down for reward, which was especially evident in male adolescents. The observed divergence of females and males in the learning capability related to the slow condition could probably be ascribed to a hormonal sex-difference. Hormonal testosterone concentrations differed significantly between females and males who showed enhanced concentrations. The varying increase of gonadal hormones during puberty could thus be one reason for the different RT adjustments in the slow clock. Accordingly, testosterone was associated with a slower RT and enhanced NoGo learning in adolescents. An explorative analysis showed that this result could be traced back to the male adolescents, most likely because testosterone is the main acting gonadal hormone during male pubertal development and by far more variable in pubertal males than in females. In line with adult research, $\mathrm{E}_{2}$ seemed to stimulate the initially faster responses and therefore Go learning in all adolescents. We speculate that the effect of $E_{2}$ could have been mediated by its modulatory impact on dopaminergic transmission, which has been assumed for similar findings in adult women (see i.a. Diekhof, 2015; Reimers et al., 2014). Estrogen receptors can be found in the brain of both sexes via which $\mathrm{E}_{2}$ presumably has modulating effects on neurotransmission and plasticity (Gillies \& McArthur, 2010).

The correlation between Go learning and $\mathrm{E}_{2}$ occurred exclusively in the initial block during which participants were still naïve regarding the temporal reward associations of the different clocks. This might indicate that $\mathrm{E}_{2}$ has only a subtle effect on behavioral responding in 
364 the clock task. Once the RT had been optimized in later phases of the task, this correlation was

365

366

367

368

369

370

371

372

373

374

375

376

377

378

379

380

381

382

383

384

385

386

387

388

389

390

391

392

393

394

395

396

397

398

399

400

401

402

403

404

405

406

407

408

409 no longer behaviorally measurable (see also Reimers et al., 2014).

Alternatively, $\mathrm{E}_{2}$ may also support learning through a promotion of signal transduction. $\mathrm{E}_{2}$ administration in young and aged ovariectomized rhesus monkeys led to an increase in spine density in the dorsolateral prefrontal cortex (Hao et al., 2003). An increased spine density on pyramidal neurons is connected to an enhanced number of excitatory synapses per neuron which in turn might improve learning performance in general (Mahmmoud et al., 2015). Moreover, in ovariectomized rats $\mathrm{E}_{2}$ administration provoked cell proliferation and an increase of dendritic spine density in the hippocampus (Adams et al., 2002; Tanapat et al., 2005). In a previous study, Davidow and colleagues (2016) demonstrated the positive impact of hippocampal activity and its connectivity to the striatum on reinforcement learning in adolescents (Davidow et al., 2016). Therefore, the potentiating influence of $\mathrm{E}_{2}$ on the hippocampus may improve reward learning as well. Besides $\mathrm{E}_{2}$, androgens also positively affect prefrontal and hippocampal processing, but rat studies indicate a greater impact of androgens in males (Hamson et al., 2016).

Similar to $\mathrm{E}_{2}$, testosterone can modulate dopaminergic transmission and may also impact transmission in other neurotransmitter systems (de Souza Silva et al., 2009; Sinclair et al., 2014). The enhancing effect of testosterone on slowing ability may additionally be explained through an interaction of testosterone and serotoninergic processing in males. In male rats, testosterone administration leads to an increase of cerebral serotonin and its metabolites (de Souza Silva et al., 2009; Thiblin et al., 1999). Moreover, a positive correlation between plasma testosterone and serotonin receptor 4 level emerged, leading to the suggestion that higher testosterone is accompanied by a higher cerebral serotonin tonus (Perfalk et al., 2017). Therapeutic approaches include selective serotonin reuptake inhibitors that increase synaptic serotonin levels and modulate neuroplasticity (Kraus et al., 2017). For learning and memory formation synaptic plasticity is exceedingly important. Serotoninergic impact on human behavior and neurophysiological processes is commonly investigated through a depletion of the serotonin precursor tryptophan. Studies with healthy humans using tryptophan depletion demonstrate a slowing of responses by pharmacologically increased serotonin (e.g. Murphy et al., 2002). We observed a better slowing ability with habitually increased testosterone, which might indicate that this could have been an indirect effect of testosterone on serotoninergic transmission. This would also be in line with other studies, that found that the effect of behavioral slowing in punishment contexts, especially under high incentive motivation, disappeared, if serotonin was pharmacologically depressed (e.g. Crockett et al., 2012). Lowered serotonin concentrations after depletion have further been associated with decreased neural sensitivity to punishment (Helmbold et al., 2015). Hence, enhanced testosterone concentration might have driven NoGo learning and enabled a better slowing down for reward, through its interaction with the serotoninergic system.

Just as a recent study, we could not observe a relation between reward or punishment sensitivity and the pubertal stage (Chahal et al., 2021). A lowered response speed in further developed adolescents could be a consequence of reduced impulsivity, which may be an indicator of neurophysiological and cognitive maturation. Similar to others, we did not find an association with chronological age (Wierenga et al., 2018). Our results thus support the assumption that pubertal development is a better indicator regarding cognitive performance than chronological age.

To date, a non-invasive direct measurement of neurotransmitter processes like dopamine binding or synthesis in the adolescent human brain is not feasible. We used non-invasive 
410 measurements to determine steroid hormone concentrations and assessed the individual learning 411 ability for Go and NoGo learning. By combining both parameters, we tried to apply them as 412 indirect indicators of dopaminergic transmission. Besides $\mathrm{E}_{2}$ and testosterone other steroid

413 hormones are presumably attractive for future studies. For instance, the influence of progesterone 414 as a counterpart to $E_{2}$ on dopaminergic action may be of increased future interest. Whereas $E_{2}$ is 415 assumed to have an agonistic effect on dopaminergic transmission, progesterone supposedly 416 reduces $\mathrm{E}_{2}$ receptor density (Selcer \& Leavitt, 1988) and apparently upregulates monoamine 417 oxidase when it is administered together with $\mathrm{E}_{2}$, which mimics the luteal phase of a natural 418 menstrual cycle (Luine \& Hearns, 1990; Luine \& Rhodes, 1983). Additionally, progesterone 419 enhances gamma-aminobutyric acid induced inhibition of dopaminergic neurons (Majewska et al., 1986). Thus, an antagonistic and reducing effect of progesterone on dopaminergic transmission has been suggested (Diekhof, 2018). In future studies, the tracking of the developing menstrual cycle of the female adolescents could probably contribute to a better interpretation of the opposite effects of $\mathrm{E}_{2}$ and progesterone.

Finally, genetic predisposition as such has already been observed to affect reward sensitivity (Richards et al., 2016), and may further interact with steroid hormone level as demonstrated previously (Jakob et al., 2018; Veselic et al., 2021). In addition to previous findings on receptor and transporter polymorphisms of dopamine, serotonin and sex hormones, future studies could examine genetic interactions via genome-wide associations.

\section{Conclusion}

430

431

432

433

434

435

436

437

438

439

440

441

442

443

444

445

446

447

448

Sex hormones modulate neurophysiological processes and behavior in the context of reward processing in both adult animals and humans. Yet, evidence from adolescent populations is sparse. The present study assessed the impact of $\mathrm{E}_{2}$ and testosterone on adolescent' reinforcement learning. Similar to female adults (e.g. Diekhof, 2015), $\mathrm{E}_{2}$ promoted initial Go learning in both sexes in our adolescent sample. Testosterone, in turn, enhanced NoGo learning in males. It could be speculated that individual differences in reinforcement learning are associated with variations in these hormones during adolescence, which shift the balance between a reward and avoidance-related learning style.

Future investigations should consider further steroid hormones (e.g. cortisol, progesterone) and neurophysiological processing to specify the impact of hormonal differences on the dopaminergic mechanisms of reinforcement learning.

\section{Acknowledgments}

The authors would like to thank Angelika Kroll for her support in laboratory analyses.

\section{References}

Adams, M. M., Fink, S. E., Shah, R. A., Janssen, W. G. M., Hayashi, S., Milner, T. A., McEwen, B. S., \& Morrison, J. H. (2002). Estrogen and Aging Affect the Subcellular Distribution of Estrogen Receptor- $\alpha$ in the Hippocampus of Female Rats. Journal of Neuroscience, 22(9), 3608-3614. https://doi.org/10.1523/jneurosci.22-09-03608.2002

Becker, J. B. (1990). Direct effect of 17ß-estradiol on striatum: Sex differences in dopamine 
release. Synapse, 5(2), 157-164. https://doi.org/10.1002/syn.890050211

450

451

452

453

454

455

456

457

458

459

460

461

462

463

464

465

466

467

468

469

470

471

472

473

474

475

476

477

478

479

480

481

482

483

484

485

Castner, S. A., Xiao, L., \& Becker, J. B. (1993). Sex differences in striatal dopamine: in vivo microdialysis and behavioral studies. Brain Research, 610(1), 127-134. https://doi.org/10.1016/0006-8993(93)91225-H

Chahal, R., Delevich, K., Kirshenbaum, J. S., Borchers, L. R., Ho, T. C., \& Gotlib, I. H. (2021). Sex differences in pubertal associations with fronto-accumbal white matter morphometry: Implications for understanding sensitivity to reward and punishment. NeuroImage, 226(November 2020), 117598. https://doi.org/10.1016/j.neuroimage.2020.117598

Cherrier, M. M., Asthana, S., Plymate, S., Baker, L., Matsumoto, A. M., Peskind, E., Raskind, M. A., Brodkin, K., Bremner, W., Petrova, A., LaTendresse, S., \& Craft, S. (2001). Testosterone supplementation improves spatial and verbal memory in healthy older men. Neurology, 57(1), 80-88. https://doi.org/10.1212/WNL.57.1.80

Crockett, M. J., Clark, L., Apergis-Schoute, A. M., Morein-Zamir, S., \& Robbins, T. W. (2012). Serotonin modulates the effects of pavlovian aversive predictions on response vigor. Neuropsychopharmacology, 37(10), 2244-2252. https://doi.org/10.1038/npp.2012.75

Davidow, J. Y., Foerde, K., Galván, A., \& Shohamy, D. (2016). An Upside to Reward Sensitivity: The Hippocampus Supports Enhanced Reinforcement Learning in Adolescence. Neuron, 92(1), 93-99. https://doi.org/10.1016/j.neuron.2016.08.031

de Souza Silva, M. A., Mattern, C., Topic, B., Buddenberg, T. E., \& Huston, J. P. (2009). Dopaminergic and serotonergic activity in neostriatum and nucleus accumbens enhanced by intranasal administration of testosterone. European Neuropsychopharmacology, 19(1), 5363. https://doi.org/10.1016/j.euroneuro.2008.08.003

Diekhof, E. K. (2015). Be quick about it. Endogenous estradiol level, menstrual cycle phase and trait impulsiveness predict impulsive choice in the context of reward acquisition. Hormones and Behavior, 74, 186-193. https://doi.org/10.1016/j.yhbeh.2015.06.001

Diekhof, E. K. (2018). Estradiol and the reward system in humans. Current Opinion in Behavioral Sciences, 23, 58-64. https://doi.org/10.1016/j.cobeha.2018.03.010

Frank, M. J., Seeberger, L. C., \& O’Reilly, R. C. (2004). By Carrot or by Stick: Cognitive Reinforcement Learning in Parkinsonism. Science, 306(5703), 1940-1943. https://doi.org/10.1126/science.1102941

Gillies, G. E., \& McArthur, S. (2010). Estrogen Actions in the Brain and the Basis for Differential Action in Men and Women: A Case for Sex-Specific Medicines. Pharmacological Reviews, 62(2), 155-198. https://doi.org/10.1124/pr.109.002071

Halari, R., Mines, M., Kumari, V., Mehrotra, R., Wheeler, M., Ng, V., \& Sharma, T. (2005). Sex differences and individual differences in cognitive performance and their relationship to endogenous gonadal hormones and gonadotropins. Behavioral Neuroscience, 119(1), 104117. https://doi.org/10.1037/0735-7044.119.1.104

Peer) reviewing PDF | (2021:04:60632:2:0:NEW 19 Nov 2021) 
486

487

488

489

490

491

492

493

494

495

496

497

498

499

500

501

502

503

504

505

506

507

508

509

510

511

512

513

514

515

516

517

518

519

520

521

522

523

Hamson, D. K., Roes, M. M., \& Galea, L. A. M. (2016). Sex Hormones and Cognition: Neuroendocrine Influences on Memory and Learning. Comprehensive Physiology, 6(3), 1295-1337. https://doi.org/10.1002/cphy.c150031

Hao, J., Janssen, W. G. M., Tang, Y., Roberts, J. A., McKay, H., Lasley, B., Allen, P. B., Greengard, P., Rapp, P. R., Kordower, J. H., Hof, P. R., \& Morrison, J. H. (2003). Estrogen increases the number of spinophilin-immunoreactive spines in the hippocampus of young and aged female rhesus monkeys. Journal of Comparative Neurology, 465(4), 540-550. https://doi.org/10.1002/cne.10837

Hartmann, A. S., Rief, W., \& Hilbert, A. (2011). Psychometric Properties of the German Version of the Barratt Impulsiveness Scale, Version 11 (Bis-11) for Adolescents. Perceptual and Motor Skills, 112(2), 353-368. https://doi.org/10.2466/08.09.10.PMS.112.2.353-368

Helmbold, K., Zvyagintsev, M., \& Dahmen, B. (2015). Effects of serotonin depletion on punishment processing in the orbitofrontal and anterior cingulate cortices of healthy women. European Neuropsychopharmacology, 25(6), 846-856. https://doi.org/10.1016/j.euroneuro.2015.02.007

Herting, M. M., Gautam, P., Spielberg, J. M., Kan, E., Dahl, R. E., \& Sowell, E. R. (2014). The role of testosterone and estradiol in brain volume changes across adolescence: A longitudinal structural MRI study. Human Brain Mapping, 35(11), 5633-5645. https://doi.org/10.1002/hbm.22575

Jakob, K., Ehrentreich, H., Holtfrerich, S. K. C., Reimers, L., \& Diekhof, E. K. (2018). DAT1Genotype and Menstrual Cycle, but Not Hormonal Contraception, Modulate Reinforcement Learning: Preliminary Evidence. Frontiers in Endocrinology, 9(60), 1-13. https://doi.org/10.3389/fendo.2018.00060

Khaleghi, M., Rajizadeh, M. A., Bashiri, H., Kohlmeier, K. A., Mohammadi, F., Khaksari, M., \& Shabani, M. (2021). Estrogen attenuates physical and psychological stress-induced cognitive impairments in ovariectomized rats. Brain and Behavior, 11(5), 1-15. https://doi.org/10.1002/brb3.2139

Kirkpatrick, S. W., Campbell, P. S., Wharry, R. E., \& Robinson, S. L. (1993). Salivary testosterone in children with and without learning disabilities. Physiology and Behavior, 53(3), 583-586. https://doi.org/10.1016/0031-9384(93)90156-A

Kohne, S., Reimers, L., Müller, M., \& Diekhof, E. K. (2021). Daytime and season do not affect reinforcement learning capacity in a response time adjustment task. Chronobiology International, 00(00), 1-7. https://doi.org/10.1080/07420528.2021.1953048

Kraus, C., Castrén, E., Kasper, S., \& Lanzenberger, R. (2017). Serotonin and neuroplasticity Links between molecular, functional and structural pathophysiology in depression. Neuroscience and Biobehavioral Reviews, 77, 317-326. https://doi.org/10.1016/j.neubiorev.2017.03.007

Ladouceur, C. D., Kerestes, R., Schlund, M. W., Shirtcliff, E. A., Lee, Y., \& Dahl, R. E. (2019). 
524

525

526

527

528

529

530

531

532

533

534

535

536

537

538

539

540

541

542

543

544

545

546

547

548

549

550

551

552

553

554

555

556

557

558

559

560

Neural systems underlying reward cue processing in early adolescence: The role of puberty and pubertal hormones. Psychoneuroendocrinology, 102(December 2018), 281-291. https://doi.org/10.1016/j.psyneuen.2018.12.016

Luine, V., \& Hearns, M. (1990). Relationship of Gonadal Hormone Administration, Sex, Reproductive Status and Age to Monoamine Oxidase Activity Within the Hypothalamus. Journal of Neuroendocrinology, 2(4), 423-428. https://doi.org/10.1111/j.13652826.1990.tb00427.x

Luine, V., \& Rhodes, J. (1983). Gonadal hormone regulation of MAO and other enzymes in hypothalamic areas. Neuroendocrinology, 36(3), 235-241. https://doi.org/10.1159/000123461

Mahmmoud, R. R., Sase, S., Aher, Y. D., Sase, A., Gröger, M., Mokhtar, M., Höger, H., \& Lubec, G. (2015). Spatial and working memory is linked to spine density and mushroom spines. PLoS ONE, 10(10), 1-15. https://doi.org/10.1371/journal.pone.0139739

Maia, T. V., \& Frank, M. J. (2011). From reinforcement learning models to psychiatric and neurological disorders. Nature Neuroscience, 14(2), 154-162. https://doi.org/10.1038/nn.2723

Majewska, M. D., Harrison, N. L., Schwartz, R. D., Barker, J. L., \& Paul, S. M. (1986). Steroid hormone metabolites are barbiturate-like modulators of the GABA receptor. Science, 232(4753), 1004-1007. https://doi.org/10.1126/science.2422758

Morris, R. W., Purves-Tyson, T. D., Weickert, C. S., Rothmond, D., Lenroot, R., \& Weickert, T. W. (2015). Testosterone and reward prediction-errors in healthy men and men with schizophrenia. Schizophrenia Research, 168(3), 649-660. https://doi.org/10.1016/j.schres.2015.06.030

Moustafa, A. A., Cohen, M. X., Sherman, S. J., \& Frank, M. J. (2008). A Role for Dopamine in Temporal Decision Making and Reward Maximization in Parkinsonism. Journal of Neuroscience, 28(47), 12294-12304. https://doi.org/10.1523/JNEUROSCI.3116-08.2008.A

Murphy, F., Smith, K., Cowen, P., Robbins, T., \& Sahakian, B. (2002). The effects of tryptophan depletion on cognitive and affective processing in healthy volunteers. Psychopharmacology, 163(1), 42-53. https://doi.org/10.1007/s00213-002-1128-9

Op de Macks, Z. A. Z. A., Bunge, S. A., Bell, O. N., Wilbrecht, L., Kriegsfeld, L. J., Kayser, A. S., \& Dahl, R. E. (2016). Risky decision-making in adolescent girls: The role of pubertal hormones and reward circuitry. Psychoneuroendocrinology, 74, 77-91. https://doi.org/10.1016/j.psyneuen.2016.08.013

Ostatníková, D., Celec, P., Putz, Z., Hodosy, J., Schmidt, F., Laznibatová, J., \& Kúdela, M. (2007). Intelligence and salivary testosterone levels in prepubertal children. Neuropsychologia, 45(7), 1378-1385. https://doi.org/10.1016/j.neuropsychologia.2006.10.018 
561 Pasqualini, C., Olivier, V., Guibert, B., Frain, O., \& Leviel, V. (1995). Acute stimulatory effect

562

563

564

565

566

567

568

569

570

571

572

573

574

575

576

577

578

579

580

581

582

583

584

585

586

587

588

589

590

591

592

593

594

595

596

597

Peper, J. S., Brouwer, R. M., Schnack, H. G., van Baal, G. C., van Leeuwen, M., van den Berg, S. M., Delemarre-Van de Waal, H. A., Boomsma, D. I., Kahn, R. S., \& Hulshoff Pol, H. E. (2009). Sex steroids and brain structure in pubertal boys and girls.

Psychoneuroendocrinology, 34(3), 332-342.

https://doi.org/10.1016/j.psyneuen.2008.09.012

Peper, J. S., \& Dahl, R. E. (2013). The Teenage Brain: Surging Hormones-Brain-Behavior Interactions During Puberty. In Current Directions in Psychological Science. https://doi.org/10.1177/0963721412473755

Peper, J. S., Hulshoff Pol, H. E., Crone, E. A., \& van Honk, J. (2011). Sex steroids and brain structure in pubertal boys and girls: A mini-review of neuroimaging studies. Neuroscience, 191, 28-37. https://doi.org/10.1016/j.neuroscience.2011.02.014

Perfalk, E., Cunha-Bang, S. da, Holst, K. K., Keller, S., Svarer, C., Knudsen, G. M., \& Frokjaer, V. G. (2017). Testosterone levels in healthy men correlate negatively with serotonin 4 receptor binding. Psychoneuroendocrinology, 81, 22-28. https://doi.org/10.1016/j.psyneuen.2017.03.018

Petersen, A. C., Crockett, L., Richards, M., \& Boxer, A. (1988). A self-report measure of pubertal status: Reliability, validity, and initial norms. Journal of Youth and Adolescence, 17(2), 117-133. https://doi.org/10.1007/BF01537962

Purves-Tyson, T. D., Handelsman, D. J., Double, K. L., Owens, S. J., Bustamante, S., \& Weickert, C. S. (2012). Testosterone regulation of sex steroid-related mRNAs and dopamine-related mRNAs in adolescent male rat substantia nigra. BMC Neuroscience, 13(1). https://doi.org/10.1186/1471-2202-13-95

Reimers, L., Büchel, C., \& Diekhof, E. K. (2014). How to be patient. The ability to wait for a reward depends on menstrual cycle phase and feedback-related activity. Frontiers in Neuroscience, 8(DEC), 1-12. https://doi.org/10.3389/fnins.2014.00401

Richards, J. S., Arias Vásquez, A., von Rhein, D., Van Der Meer, D., Franke, B., Hoekstra, P. J., Heslenfeld, D. J., Oosterlaan, J., Faraone, S. V., Buitelaar, J. K., \& Hartman, C. A. (2016). Adolescent behavioral and neural reward sensitivity: a test of the differential susceptibility theory. Translational Psychiatry, 6(4), e771. https://doi.org/10.1038/tp.2016.37

Selcer, K. W., \& Leavitt, W. W. (1988). Progesterone down-regulation of nuclear estrogen receptor: A fundamental mechanism in birds and mammals. General and Comparative Endocrinology, 72(3), 443-452. https://doi.org/10.1016/0016-6480(88)90167-0

Sinclair, D., Purves-Tyson, T. D., Allen, K. M., \& Weickert, C. S. (2014). Impacts of stress and sex hormones on dopamine neurotransmission in the adolescent brain.

Psychopharmacology, 231(8), 1581-1599. https://doi.org/10.1007/s00213-013-3415-z

Peer] reviewing PDF | (2021:04:60632:2:0:NEW 19 Nov 2021) 
598

599

600

601

602

603

604

605

606

607

608

609

610

611

612

613

614

615

616

617

618

619

620

621

622

623

624

625

626

627

628

629

630

Sisk, C. L., \& Foster, D. L. (2004). The neural basis of puberty and adolescence. Nature Neuroscience, 7(10), 1040-1047. https://doi.org/10.1038/nn1326

Spritzer, M. D., Daviau, E. D., Coneeny, M. K., Engelman, S. M., Prince, W. T., \& RodriguezWisdom, K. N. (2011). Effects of testosterone on spatial learning and memory in adult male rats. Hormones and Behavior, 59(4), 484-496. https://doi.org/10.1016/j.yhbeh.2011.01.009

Stiensmeier-Pelster, J., Braune-Krickau, M., Schürmann, M., \& Duda, K. (2014).

Depressionsinventar für Kinder und Jugendliche (DIKJ). In M. A. Wirtz (Ed.), DorschLexikon der Psychologie (18., p. 366). Verlag Hogrefe Verlag.

Tanapat, P., Hastings, N. B., \& Gould, E. (2005). Ovarian steroids influence cell proliferation in the dentate gyrus of the adult female rat in a dose- and time-dependent manner. Journal of Comparative Neurology, 481(3), 252-265. https://doi.org/10.1002/cne.20385

Thiblin, I., Finn, A., Ross, S. B., \& Stenfors, C. (1999). Increased dopaminergic and 5hydroxytryptaminergic activities in male rat brain following long-term treatment with anabolic androgenic steroids. British Journal of Pharmacology, 126(6), 1301-1306. https://doi.org/10.1038/sj.bjp.0702412

Veselic, S., Jocham, G., Gausterer, C., Wagner, B., Ernhoefer-Reßler, M., Lanzenberger, R., Eisenegger, C., Lamm, C., \& Losecaat Vermeer, A. (2021). A causal role of estradiol in human reinforcement learning. Hormones and Behavior, 134(August 2020). https://doi.org/10.1016/j.yhbeh.2021.105022

Wechsler, D. (2014). WISC-V Wechsler intelligence scale for children - fith edition (F. Petermann (ed.); 5th ed.). Pearson.

White, S. F., Lee, Y., Schlund, M. W., Shirtcliff, E. A., \& Ladouceur, C. D. (2020). Testosterone Reactivity is Associated with Reduced Neural Response to Reward in Early Adolescence. Behavioural Brain Research, 387(112593). https://doi.org/10.1016/j.bbr.2020.112593.Testosterone

Wierenga, L. M., Bos, M. G. N., Schreuders, E., vd Kamp, F., Peper, J. S., Tamnes, C. K., \& Crone, E. A. (2018). Unraveling age, puberty and testosterone effects on subcortical brain development across adolescence. Psychoneuroendocrinology, 91(March), 105-114. https://doi.org/10.1016/j.psyneuen.2018.02.034

Wood, R. I., Armstrong, A., Fridkin, V., Shah, V., Najafi, A., \& Jakowec, M. (2013). 'Roid rage in rats? Testosterone effects on aggressive motivation, impulsivity and tyrosine hydroxylase. Physiology and Behavior, 0, 6-12.

631 


\section{Scheme 1}

Task design

Fig. 1 A. Reward was calculated using cosine functions for the fast and slow clock. A timeindependent function for the random clock was applied as control condition. B. Clock faces were presented pseudo-randomly for $5000 \mathrm{~ms}$. Once a button press was made, the clock arm stopped, and immediate feedback was given. After that, a blank screen was shown for the remaining time that the clock arm would have need to complete the $5000 \mathrm{~ms}$. Therefore, the blank screen ensures a constant time duration of a trial. A trial ended with the achieved points presented $1000 \mathrm{~ms}$.
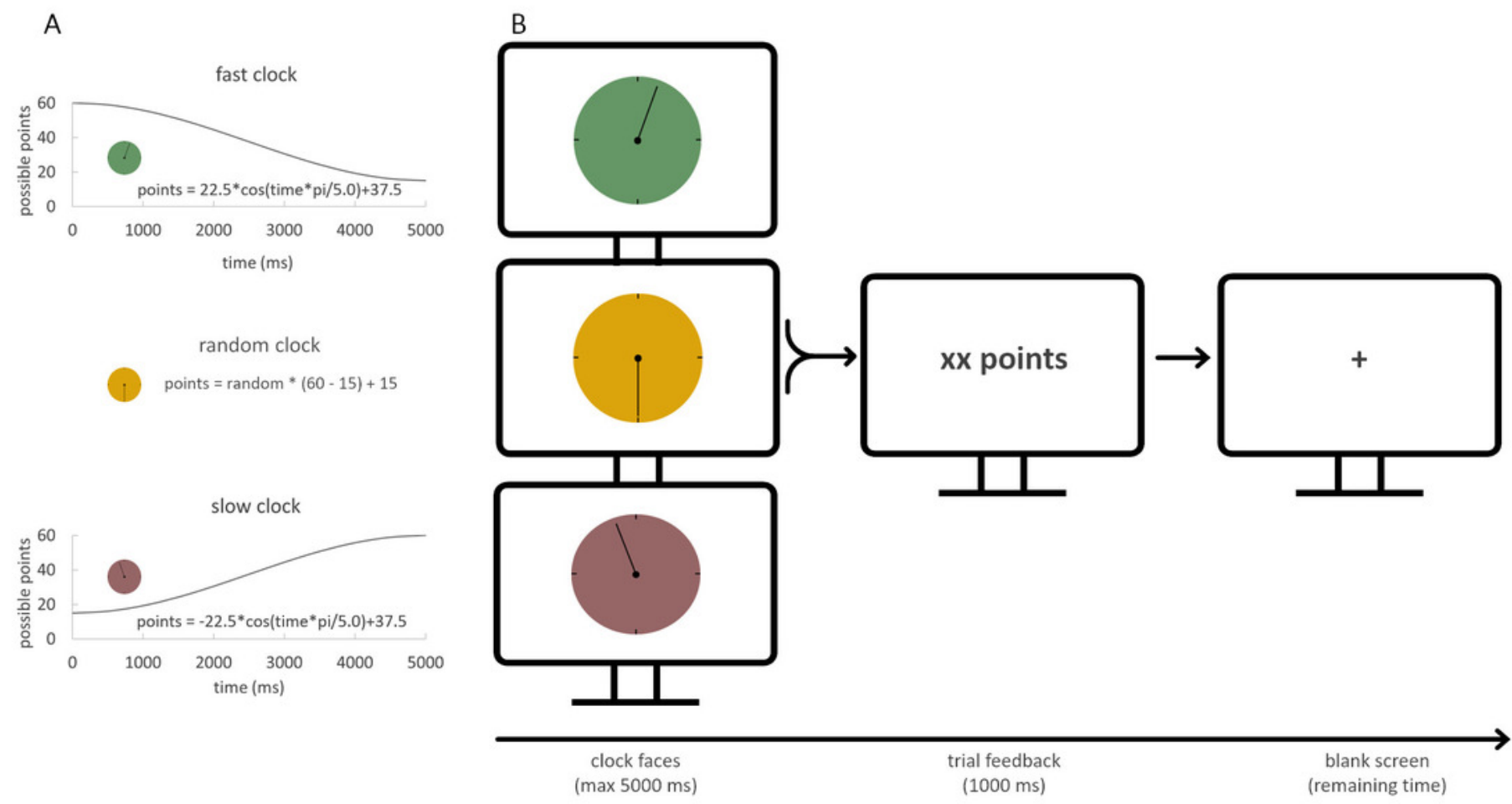
Figure 1

Reverse relation of slowing and speeding.

Optimized relative speeding and slowing were negatively correlated in females, and males ( $p$ $<.001)$.

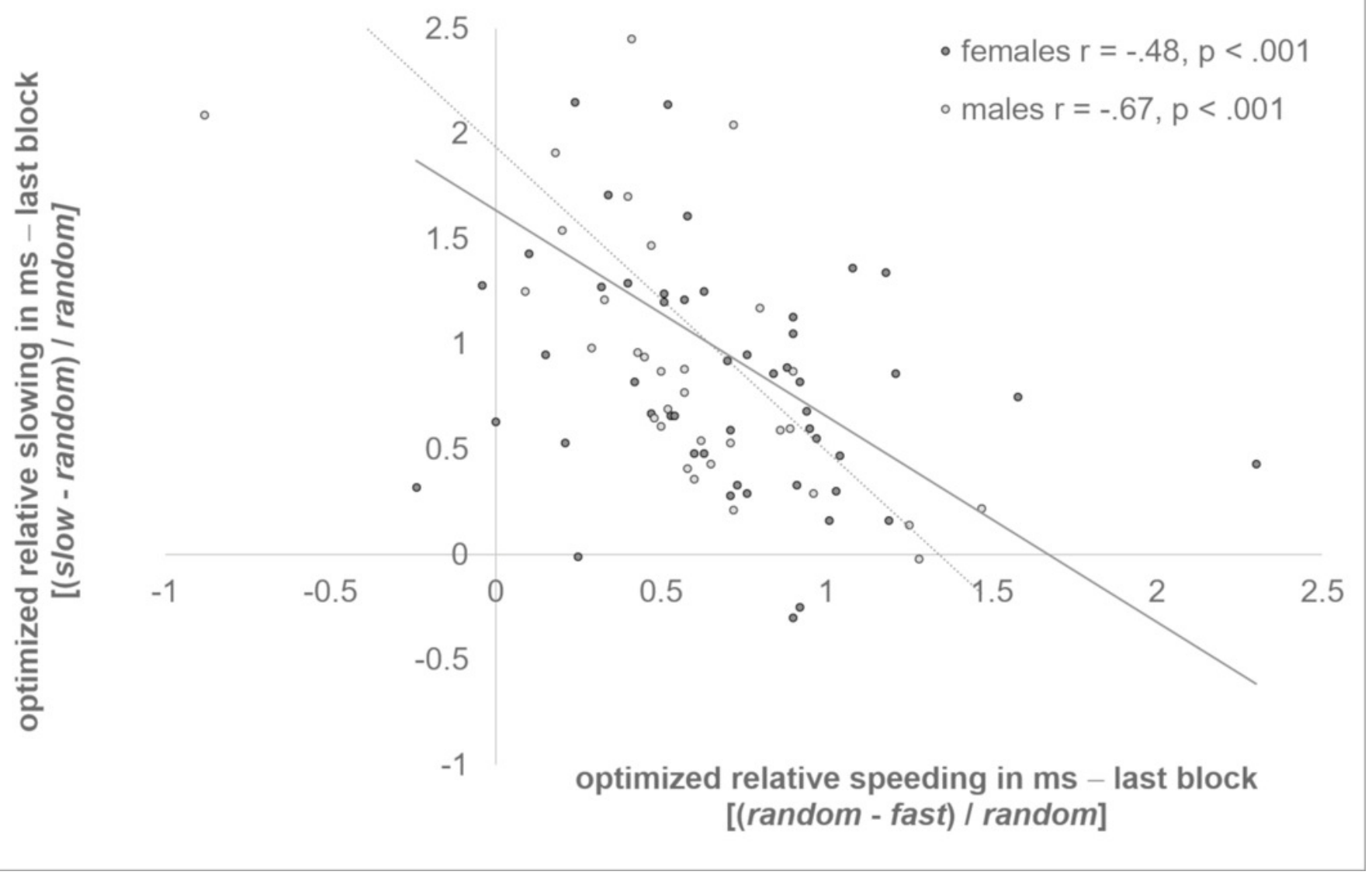


Figure 2

Negative correlation between $\mathrm{zE}_{2}$ and the initial fast clock.

Subjects who had higher $\mathrm{zE}_{2}$ concentrations responded faster during the initial fast clock condition $(r=-.24, p=.03)$.

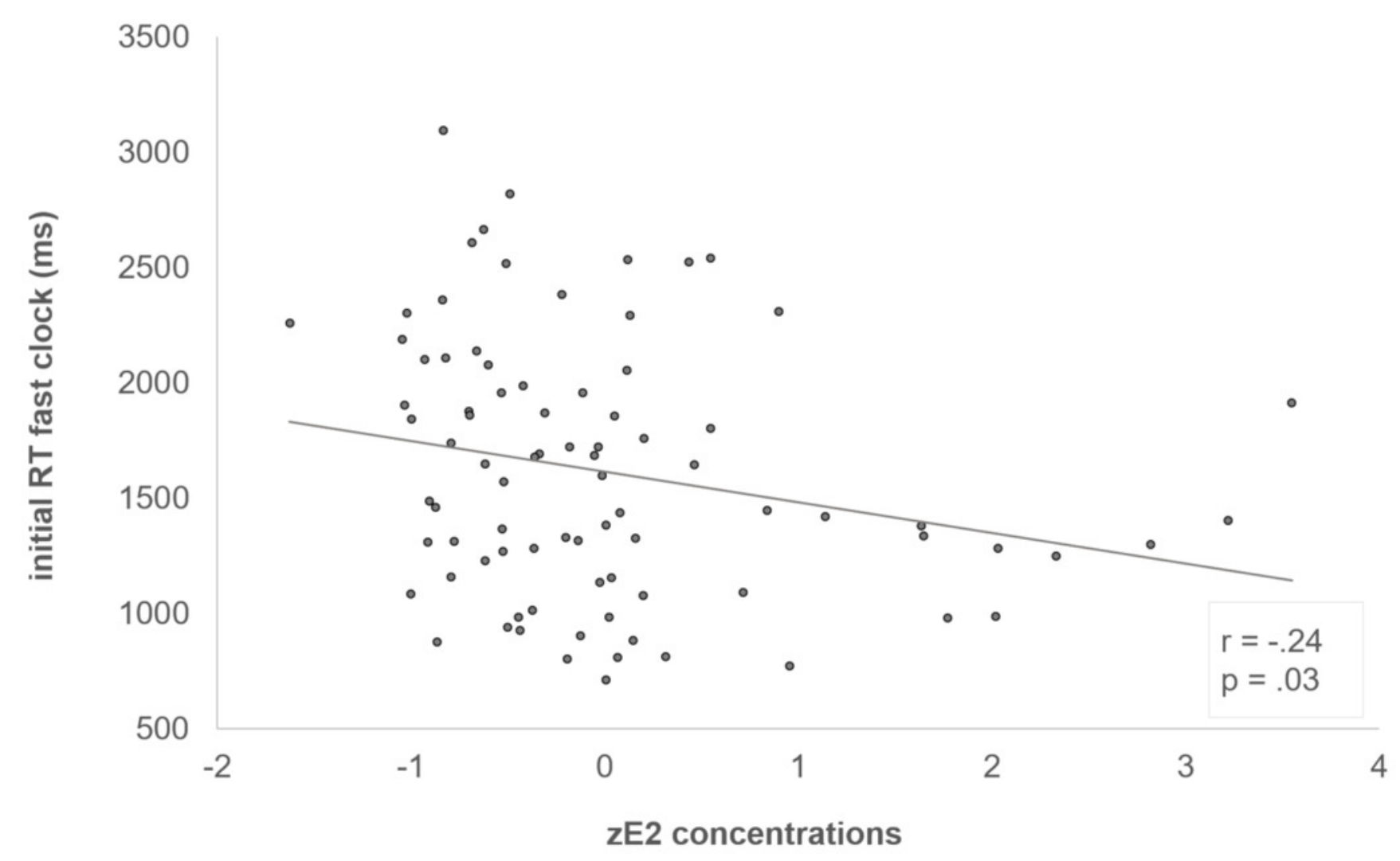


Figure 3

Positive correlation between $\mathrm{ZE}_{2}$ and the learning-related change of the fast clock.

Subjects who had lower $\mathrm{zE}_{2}$ concentrations showed a higher adjustment from the initial to the optimized block in the fast clock condition $(r=.28, p=.01)$.

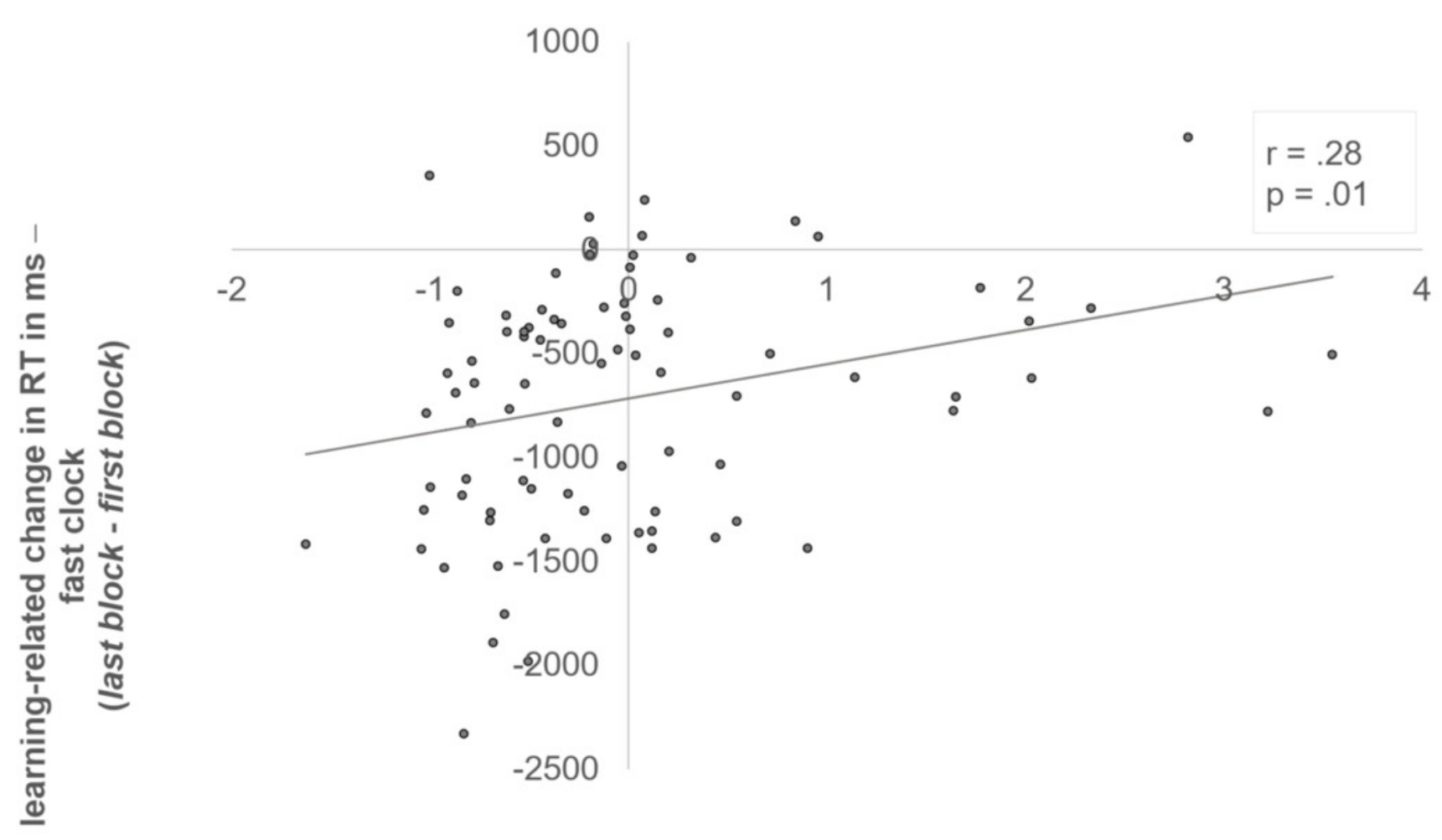

zE2 concentrations 
Figure 4

Positive correlation between zT and the response time of all clocks and both blocks.

Subjects who had higher zT concentrations responded generally slower $(r=.29, p=.007)$.

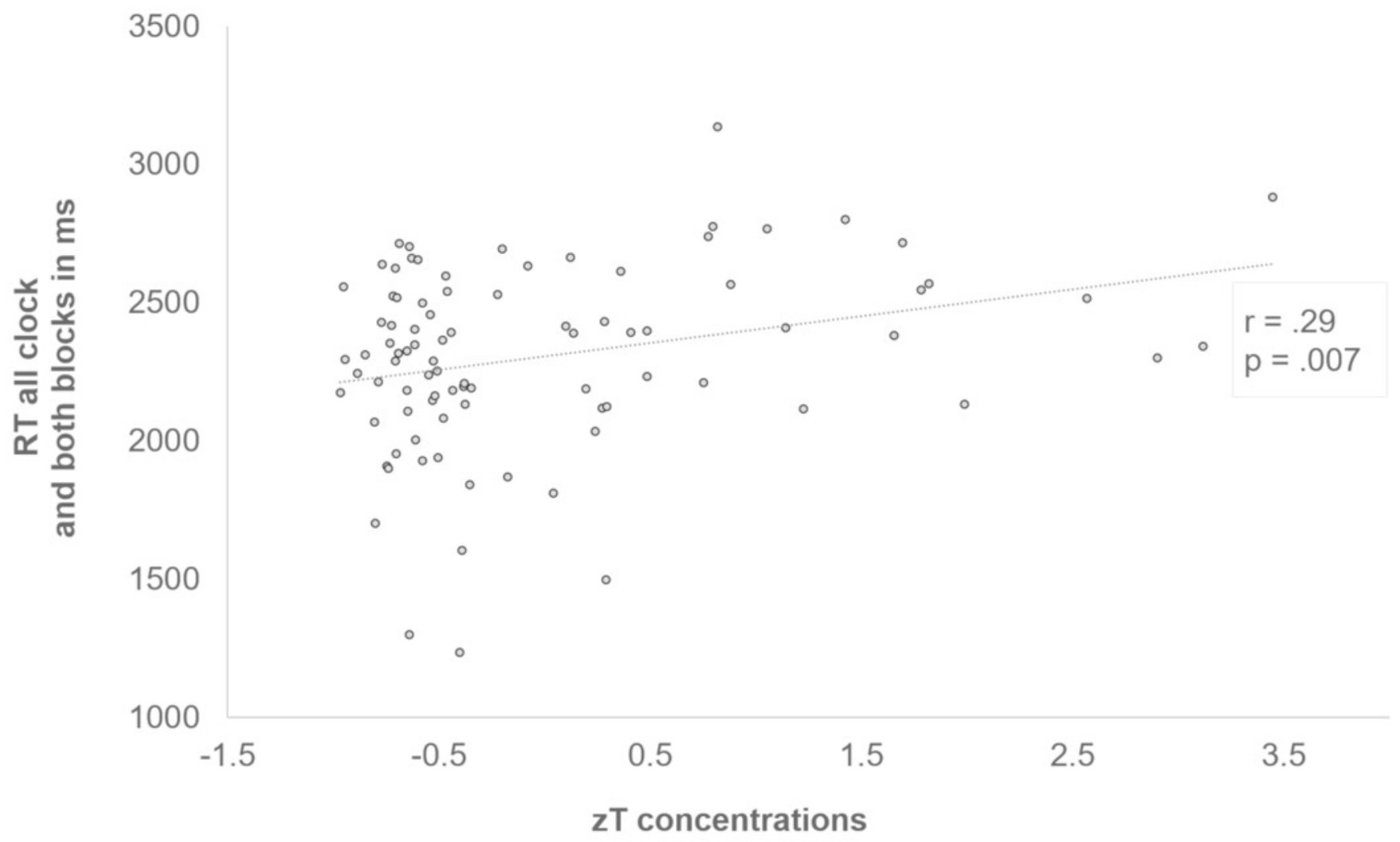


Table $\mathbf{1}$ (on next page)

Group differences by sex 


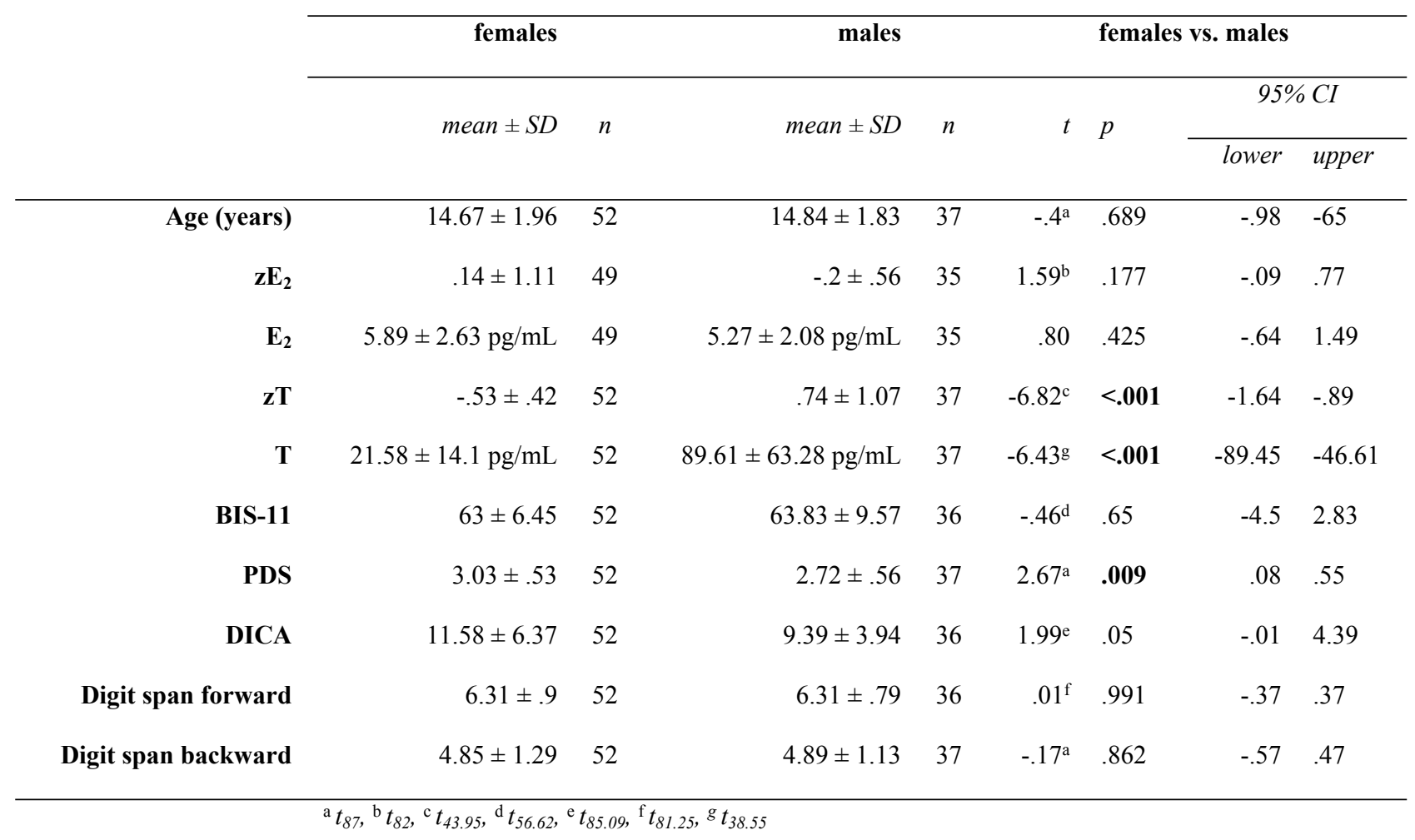

\section{Table 1 Group differences by sex}

2 
Table 2 (on next page)

Comprehensive summary of RTs and post-hoc results 


\section{Table 2 Comprehensive summary of RTs and post-hoc results}

\begin{tabular}{|c|c|c|c|c|c|c|c|c|c|c|c|c|c|c|}
\hline \multirow{3}{*}{ block } & \multirow{3}{*}{ clock } & \multicolumn{3}{|c|}{ mean $\mathbf{R T} \pm \mathbf{S E}$} & \multicolumn{4}{|c|}{ females vs. males } & \multicolumn{6}{|c|}{ correlations of all participants } \\
\hline & & \multirow{2}{*}{ females \& males } & \multirow{2}{*}{ females } & \multirow{2}{*}{ males } & \multirow{2}{*}{$t(d f=87)$} & \multirow{2}{*}{$p$} & \multicolumn{2}{|c|}{$95 \% C I$} & \multicolumn{2}{|c|}{$z T$} & \multicolumn{2}{|c|}{$z E_{2}$} & \multicolumn{2}{|c|}{$P D S$} \\
\hline & & & & & & & lower & upper & $r$ & $p$ & $r$ & $p$ & $r$ & $p$ \\
\hline \multirow[t]{4}{*}{$\begin{array}{l}\text { first } \\
\& \text { last }\end{array}$} & FAST & $1264 \pm 37 \mathrm{~ms} \mathrm{ab}^{* * * *}$ & $1302 \pm 54 \mathrm{~ms}$ & $\begin{array}{l}1212 \pm \\
293 \mathrm{~ms}\end{array}$ & 1.2 & .234 & $-60 \mathrm{~ms}$ & $241 \mathrm{~ms}$ & -.12 & .327 & -.08 & .497 & -.12 & .274 \\
\hline & RANDOM & $2196 \pm 65 \mathrm{~ms} \mathrm{ac}^{* * * *}$ & $2157 \pm 562 \mathrm{~ms}$ & $\begin{array}{l}2253 \pm \\
695 \mathrm{~ms}\end{array}$ & -.71 & .477 & $-360 \mathrm{~ms}$ & $170 \mathrm{~ms}$ & .23 & $.032^{2 * *}$ & -.02 & .843 & .19 & $.068^{*}$ \\
\hline & SLOW & $3458 \pm 67 \mathrm{~ms} \mathrm{bc}^{\mathrm{bc} * *}$ & $3346 \pm 653 \mathrm{~ms}^{\mathrm{d}} \mathrm{d}^{* *}$ & $\begin{array}{l}3617 \pm \\
593 \mathrm{~ms}^{\mathrm{d}^{* * *}}\end{array}$ & -2 & $.048^{* *}$ & $-539 \mathrm{~ms}$ & $-2 \mathrm{~ms}$ & .28 & $.009^{9 *}$ & -.04 & .731 & .1 & .359 \\
\hline & ALL CLOCKS & $2307 \pm 333 \mathrm{~ms}$ & $2269 \pm 311 \mathrm{~ms}$ & $\begin{array}{l}2360 \pm \\
360 \mathrm{~ms}\end{array}$ & -1.28 & .203 & $-234 \mathrm{~ms}$ & $50 \mathrm{~ms}$ & .29 & $.007^{7 * *}$ & -.09 & .412 & .14 & .185 \\
\hline \multirow[t]{3}{*}{ first } & FAST & $1610 \pm 58 \mathrm{~ms} \mathrm{~d}^{\mathrm{d} * * *}$ & $1655 \pm 571 \mathrm{~ms}$ & $\begin{array}{l}1547 \pm \\
524 \mathrm{~ms}\end{array}$ & .92 & .363 & $-127 \mathrm{~ms}$ & $345 \mathrm{~ms}$ & -.08 & .441 & -.24 & $.03^{* * *}$ & -.12 & .249 \\
\hline & RANDOM & $2203 \pm 78 \mathrm{~ms}$ & $2104 \pm 685 \mathrm{~ms}$ & $\begin{array}{l}2343 \pm \\
794 \mathrm{~ms}\end{array}$ & -1.52 & .132 & $-552 \mathrm{~ms}$ & $73 \mathrm{~ms}$ & .18 & $.084^{*}$ & .08 & .469 & .1 & .354 \\
\hline & SLOW & $2945 \pm 87 \mathrm{~ms} \mathrm{e}^{* * * *}$ & $2791 \pm 807 \mathrm{~ms}^{\mathrm{f}^{* *}}$ & $\begin{array}{l}3163 \pm \\
803 \mathrm{~ms}^{\mathrm{p}^{* *}}\end{array}$ & -2.15 & $.034^{* *}$ & $-717 \mathrm{~ms}$ & $-29 \mathrm{~ms}$ & .3 & $.004^{* * *}$ & -.06 & .572 & .1 & .366 \\
\hline \multirow[t]{4}{*}{ last } & FAST & $919 \pm 36 \mathrm{~ms} \mathrm{~d}^{\mathrm{d}^{* * * *}}$ & $949 \pm 382 \mathrm{~ms}$ & $\begin{array}{l}877 \pm \\
275 \mathrm{~ms}\end{array}$ & 1.04 & .3 & $-74 \mathrm{~ms}$ & $219 \mathrm{~ms}$ & -.04 & .718 & .1 & .383 & -.04 & .692 \\
\hline & RANDOM & $2190 \pm 80 \mathrm{~ms}$ & $2211 \pm 703 \mathrm{~ms}$ & $\begin{array}{l}2162 \pm \\
834 \mathrm{~ms}\end{array}$ & 0.3 & .765 & $-276 \mathrm{~ms}$ & $374 \mathrm{~ms}$ & -.14 & .195 & -.12 & .275 & .22 & $.038^{* *}$ \\
\hline & SLOW & $3972 \pm 66 \mathrm{~ms}^{\mathrm{e}^{* * * *}}$ & $3902 \pm 694 \mathrm{~ms}$ & $\begin{array}{l}4071 \pm \\
503 \mathrm{~ms}\end{array}$ & -1.33 & .188 & $-435 \mathrm{~ms}$ & $97 \mathrm{~ms}$ & .23 & $.03^{* *}$ & $<.01$ & .991 & .07 & .491 \\
\hline & 1 letters 1 & gnificant pairec & $<.001,{ }^{* * *} \mathrm{~F}$ & $0, p$ & 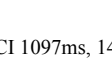 & 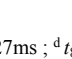 & 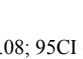 & 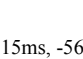 & 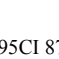 & $\mathrm{s}, 11$ & & & & \\
\hline
\end{tabular}

